\title{
Population variations of fruit flies, Bactrocera spp. in mango orchards of Hyderabad and Larkana Sindh
}

\author{
Zain-Ul-Aabdin Abro ${ }^{1 *}$, Naheed Baloch ${ }^{1}$, Raza Muhammad Memon ${ }^{2}$, \\ Niaz Hussain Khuhro ${ }^{2}$ and Qadeer Ahmed Soomro ${ }^{2}$ \\ 1. Department of Zoology, University of Sindh, Jamshoro, Sindh-Pakistan \\ 2. Nuclear Institute of Agriculture (NIA), Tando Jam, Sindh-Pakistan \\ *Corresponding author's email: zainabro128@gmail.com
}

Citation

Zain-Ul-Aabdin Abro ${ }^{*}$, Naheed Baloch ${ }^{1}$, Raza Muhammad Memon ${ }^{2}$ Niaz Hussain Khuhro ${ }^{2}$, and Qadeer Ahmed Soomro. Population variations of fruit flies, Bactrocera spp. in mango orchards of Hyderabad and Larkana Sindh. Vol. 9, Issue 1, pp949-955. http://dx.doi.org/10.19045/bspab.2020.90099

\begin{tabular}{|c|c|c|c|}
\hline Received: 28/10/2019 & Revised: 30/12/2019 & Accepted: 07/01/2020 & Online First: 09/01/2020 \\
\hline
\end{tabular}

\section{Abstract}

Studies were undertaken during 2018 on population fluctuations of Bactrocera fruit flies on mango orchard plants in parts of two districts (Hyderabad and Larkana) of Sindh Province. Investigations were carried out using methyl eugenol lured traps. The male lure tempted traps were erected at three meter height and replenished on fortnightly basis. Results revealed that significantly higher population of $B$. zonata flies per trap were recorded in the month of June in mango orchards of district Hyderabad and Larkana as $658.6 \pm 20.26$ flies, $601.9 \pm 25.38$ flies, respectively. B. dorsalis $(447.4 \pm 18.3,396.9 \pm 38.79)$ population in June at both sites. Moreover, lowest population of both species as $7.7 \pm 0.96$ and $5.9 \pm 0.97$ flies per trap were recorded in the month of December at site in Larkana. On contrary lower number of flies per trap as $12.9 \pm 1.35$, and $9.5 \pm 0.45$ of $B$. zonata and B. dorsalis were observed in the month of January in mango orchard of Hyderabad district. Both species were positively correlated with the temperature while negatively correlated to relative humidity. Results of the present investigation would be helpful in developing sustainable male annihilation technique (MAT) which is an important component in integrated pest management program (IPM) being in practice for fruit fly monitoring and control in mango orchards in Sindh.

Keywords: Bactrocera fruit flies; MAT; Methyl eugenol; Meteorological factors; Population variations

\section{Introduction}

Fruit flies (Diptera: Tephritidae) are the most injurious pests of the fruits, widely distributed across the tropics and sub tropics. In Pakistan, eleven fruit fly species have been documented attacking a variety of fruits [1, 2]. Among them Bactrocera zonata and Bactrocera dorsalis have been recorded on mango, guava, peach, banana, chicko, oranges and other fleshy fruits [3, 4]. Due to their economic impact, flies of two species were considered serious pests on mango fruit. Female flies of these species oviposit in the fruits and consequently young larvae feed on the pulp thus render the mango fruit unmarketable [5]. The fruit exports from Pakistan reduced to $\$ 382$ million during year 2016-17 as compared to $\$ 427$ million earnings of year 2015-16. Because of the stringent quality standards applied by the government when European Union imposed ban on export of mangoes from India and Pakistan. In addition, to the direct losses, the infestation of these species can limit trade value and export opportunities due to stern quarantine regulations. Pakistan stands fifth among various mango growing countries. The area under fruit orchards across the country is about 48413 hectares and the mango fruit is 
the second most exported fruits [6]. To avoid infestation of fruit flies, frequent application of pesticide is advocated in Kenya and Egypt which destroyed the natural fauna $[7,8]$. The major pest control and eradication programs have been developed in various parts of the world to combat fruit flies. The assortment of control methods comprises insecticide sprays to foliage and soil, bait-sprays, male annihilation techniques, releases of sterilized flies and parasitoids, and cultural controls [9].

We recorded population fluctuations of $B$. zonata and B. dorsalis using Steiner type traps locally known as "Tando Jam Traps" lured with methyl eugenol in mango orchards of different climatic regions of Sindh. We documented data in connection with meteorological factors to find sustainable pest management strategy against Bactrocera spp in mango orchard ecosystem.

\section{Materials and methods}

\section{Study area}

The total area of 5 acres was selected at each site of mango orchards in two districts of Sindh province i.e., Hyderabad and Larkana which were situated in discrete zones. Hyderabad is located in lower Sindh on left bank of Indus River whereas Larkana is in upper central area of Sindh on right bank of Indus River. The experiments were conducted in Mango orchards of Dehli Farm Tando Jam, 25 $25^{\prime} 60 \mathrm{~N} 68^{\circ} 31^{\prime} 60 \mathrm{E}$ Hyderabad and Bakrani, 27 $26^{\circ} 46.66^{\prime \prime} \mathrm{N}$ $68^{\circ} 11^{\prime} 07.11^{\prime \prime}$ E Larkana. For observing the population fluctuations of Bactrocera species and effect of weather parameters on it, experimental treatments were laid out in Randomized Complete Block Design (RCBD) with ten replications.

Male lured plastic made jars as "Steiner type traps" locally known as "Tando Jam Traps" that measured $20 \mathrm{~cm}$ in length and 8 $\mathrm{cm}$ in diameter were used for fly trapping during 2018. Male lure were replenished at fortnightly interval whereas record of flies per trap were made on weekly basis.
Cotton lints were soaked with $5 \mathrm{ml}$ of methyl eugenol (lure for males of fruit fly) having 5\% (Pyramid 10\% AS) insecticide suspended inside traps. Male Bactrocera flies were attracted to trap and killed by the insecticide inside traps. The captured male flies were brought to the laboratory of Plant Protection Division, Nuclear Institute of Agriculture (NIA), Tando Jam where both species of flies were identified and counted separately.

\section{Meteorological data and statistical analysis}

Meteorological data, on temperature and relative humidity, used in this study were provided by Regional AGRO-MET Centres at Tando Jam - Hyderabad and Larkana, Sindh, Pakistan.

All statistical analyses were done with the help of Statistix ${ }^{\circledR}$ Version 8.1, Analytical Software, Inc., and Tallahassee, FL, USA. Statistical analysis was done using two-way analysis of variance ANOVA for different parameters followed by Tukey's Post Hoc HSD Test for the significance of data.

\section{Results and discussion}

We have found only two Bactrocera species, i.e., Peach Fruit Fly, Bactrocera zonata, and Oriental Fruit Fly, Bactrocera dorsalis throughout the whole year of studies. The Peach fruit fly (B. zonata) was found to be the most prominent pest of mangoes and observed in maximum numbers in mango orchard agro-ecosystem of both districts of Sindh Province. During entire period of present studies, per trap population of Bactrocera flies exhibited a trend of fluctuations in both climatic zones. The highest mean numbers of peach fruit fly were recorded followed by numbers of oriental fruit fly were recorded in June at both climatic regions. Moreover, lowest fruit flies catches per trap were recorded in January at Hyderabad and in December at Larkana (Table $1 \& 2$ ). The population of Bactrocera flies positively correlated with temperature and relative humidity had negative impact on it in Hyderabad and Larkana (Table 3). 
The maximum activity of Bactrocera flies were recorded from May to June while low activity were observed from December to March in both climatic zones. Moderate population were recorded in the months of April and October in both climatic regions (Fig. 1 \& 2).

The increase in temperature encouraged the population of both species where peak populations were recorded at $39-44^{\circ} \mathrm{C}$, in both climatic zones. Whereas, temperature above $45{ }^{\circ} \mathrm{C}$ was found more precarious for the ripened fruit as it augmented the fruit flies population in studied areas. The favorable humidity $\%$ for the fruit flies were recorded between 35 to $65 \%$ (Fig. $3 \& 4$ ). The results are slightly in line with that of previous work by [10]. Population of Bactrocera flies significantly amplified when fruits were ripened, the results are similar to [11] who reported increased number of fruit flies with full grown fruit in agroecological zones of Tanzania.

Table 1. Month wise population fluctuations of Bactrocera spp. (mean no. of flies/trap $\pm \mathrm{SE}$ ) and weather data $\left({ }^{\circ} \mathrm{C}\right.$ or $\mathrm{RH} \pm \mathrm{SE}$ ) during January to December, 2018 in mango orchards of district Hyderabad.

\begin{tabular}{|c|c|c|c|c|}
\hline \multirow{2}{*}{ Month and Year } & \multicolumn{2}{|c|}{ Fruit flies species } & \multirow{2}{*}{$\begin{array}{c}\text { Max: Temp. } \\
\left({ }^{\circ} \mathrm{C}\right)\end{array}$} & \multirow{2}{*}{$\begin{array}{c}\text { Relative Humidity } \\
(\%)\end{array}$} \\
\hline & B. zonata & B. dorsalis & & \\
\hline January, 2018 & $12.9 \pm 1.35 \mathrm{f}$ & $9.5 \pm 0.45 \mathrm{e}$ & $26.48 \pm 2.45$ & $51.38 \pm 4.37$ \\
\hline February, 2018 & $17.6 \pm 1.56 \mathrm{f}$ & $14.5 \pm 1.41 \mathrm{e}$ & $28.82 \pm 3.74$ & $51.32 \pm 5.45$ \\
\hline March, 2018 & $107.8 \pm 12.48 \mathrm{e}$ & $176.4 \pm 28.89 \mathrm{~d}$ & $36.22 \pm 3.10$ & $45.61 \pm 8.03$ \\
\hline April, 2018 & $233.5 \pm 19.80 \mathrm{~d}$ & $314.2 \pm 24.95 \mathrm{bc}$ & $40.23 \pm 1.95$ & $41.73 \pm 7.43$ \\
\hline May, 2018 & $518.4 \pm 31.63 \mathrm{~b}$ & $396.9 \pm 38.79 \mathrm{ab}$ & $42.00 \pm 1.39$ & $41.19 \pm 8.13$ \\
\hline June, 2018 & $658.6 \pm 20.26$ a & $484.5 \pm 29.11 \mathrm{a}$ & $39.08 \pm 2.00$ & $57.5 \pm 6.29$ \\
\hline July, 2018 & $596.7 \pm 25.88 \mathrm{a}$ & $382.5 \pm 26.94 \mathrm{~b}$ & $37.00 \pm 1.32$ & $63.38 \pm 5.43$ \\
\hline August,2018 & $429.9 \pm 22.59 \mathrm{c}$ & $248.7 \pm 13.43 \mathrm{~cd}$ & $35.98 \pm 1.41$ & $65.09 \pm 3.96$ \\
\hline September, 2018 & $294.1 \pm 18.18 \mathrm{~d}$ & $40.3 \pm 4.09 \mathrm{e}$ & $36.8 \pm 1.91$ & $60.63 \pm 4.43$ \\
\hline October, 2018 & $60.4 \pm 6.89$ e f & $44.2 \pm 6.94 \mathrm{e}$ & $37.46 \pm 2.31$ & $50.35 \pm 6.27$ \\
\hline November, 2018 & $25.6 \pm 2.21 \mathrm{f}$ & $13.8 \pm 2.13 \mathrm{e}$ & $31.91 \pm 2.95$ & $56.6 \pm 7.24$ \\
\hline December, 2018 & $15.2 \pm 1.39 \mathrm{f}$ & $10.1 \pm 0.83 \mathrm{e}$ & $25.90 \pm 3.23$ & $59.51 \pm 5.69$ \\
\hline
\end{tabular}

Values followed by different letters are significantly differ at $5 \%$ according to Tukey's Honest Significant Difference (HSD) test.

Table 2. Month wise population fluctuations of Bactrocera spp. (mean no. of flies/trap $\pm \mathrm{SE}$ ) and weather data $\left({ }^{\circ} \mathrm{C}\right.$ or $\mathrm{RH} \pm \mathrm{SE}$ ) during January to December, 2018 in mango orchards of district Larkana.

\begin{tabular}{|c|c|c|c|c|}
\hline \multirow[b]{2}{*}{ Month and Year } & \multicolumn{2}{|c|}{ Fruit flies species } & \multirow{2}{*}{$\begin{array}{c}\text { Max: Temp. } \\
\left({ }^{\circ} \mathrm{C}\right)\end{array}$} & \multirow[b]{2}{*}{$\begin{array}{c}\text { Relative Humidity } \\
(\%)\end{array}$} \\
\hline & B. zonata & B. dorsalis & & \\
\hline January, 2018 & $8.4 \pm 0.79 \mathrm{f}$ & $6.8 \pm 0.67 \mathrm{f}$ & $24.06 \pm 1.69$ & $40.87 \pm 7.32$ \\
\hline February, 2018 & $11.1 \pm 1.36 \mathrm{f}$ & $9.3 \pm 1.04 \mathrm{f}$ & $27.33 \pm 2.69$ & $40.28 \pm 9.30$ \\
\hline March, 2018 & $104.5 \pm 15.32 \mathrm{de}$ & $91.8 \pm 2.75 \mathrm{e}$ & $35.58 \pm 4.17$ & $29.77 \pm 10.12$ \\
\hline April, 2018 & $221.6 \pm 47.25 \mathrm{c}$ & $157.1 \pm 9.52 \mathrm{~d}$ & $41.18 \pm 3.32$ & $21.96 \pm 5.63$ \\
\hline May, 2018 & $512.2 \pm 20.40 \mathrm{a}$ & $311.8 \pm 23.28 \mathrm{~b}$ & $44.41 \pm 3.05$ & $27.35 \pm 10.29$ \\
\hline June, 2018 & $601.9 \pm 25.38$ a & $447.4 \pm 18.35$ a & $44.28 \pm 3.30$ & $36.53 \pm 11.22$ \\
\hline July, 2018 & $563.8 \pm 28.69 \mathrm{a}$ & $355.7 \pm 22.59 \mathrm{~b}$ & $41.12 \pm 1.48$ & $44.00 \pm 5.40$ \\
\hline August,2018 & $396.6 \pm 13.96 \mathrm{~b}$ & $215.5 \pm 11.09 \mathrm{c}$ & $39.40 \pm 1.32$ & $46.83 \pm 5.02$ \\
\hline September, 2018 & $114.6 \pm 14.35 \mathrm{~d}$ & $88.1 \pm 7.91 \mathrm{e}$ & $37.55 \pm 1.49$ & $50.66 \pm 5.01$ \\
\hline October, 2018 & $47.6 \pm 5.70 \mathrm{def}$ & $16.2 \pm 2.35 \mathrm{f}$ & $34.82 \pm 1.93$ & $43.25 \pm 9.30$ \\
\hline November, 2018 & $18.4 \pm 1.15 \mathrm{f}$ & $9.7 \pm 1.05 \mathrm{f}$ & $30.36 \pm 1.78$ & $44.51 \pm 9.53$ \\
\hline December, 2018 & $7.7 \pm 0.96 \mathrm{f}$ & $5.9 \pm 0.97 \mathrm{f}$ & $24.25 \pm 2.34$ & $50.41 \pm 8.34$ \\
\hline
\end{tabular}

Values followed by different letters are significantly differ at $5 \%$ according to Tukey's Honest Significant Difference (HSD) test. 
Table 3. Showing Pearson's correlation between weather parameters and population fluctuations of Bactrocera zonata and Bactrocera dorsalis in mango orchards of Hyderabad and Larkana.

\begin{tabular}{|c|c|c|c|c|}
\hline \multirow{2}{*}{ Location \& Fruit Fly Species } & \multicolumn{2}{|c|}{ Meteorological factors (Correlation) } & \multirow{2}{*}{\begin{tabular}{c} 
Relative \\
\cline { 3 - 4 }
\end{tabular}} & \multicolumn{2}{|c|}{ Temp $\left({ }^{\circ} \mathbf{C}\right)$} & \\
\cline { 3 - 4 } & Minimum & Maximum & \\
\hline Hyderabad & B. zonata & $0.8957^{*}$ & $0.6976^{*}$ & -0.2280 \\
\hline Hyderabad & B. dorsalis & $0.7630^{*}$ & $0.7605^{*}$ & -0.1747 \\
\hline Larkana & B. zonata & $0.8164^{*}$ & $0.8453^{*}$ & -0.2685 \\
\hline Larkana & B. dorsalis & $0.8435^{*}$ & $0.8435^{*}$ & -0.3044 \\
\hline
\end{tabular}

*Positively significant at ( $\mathrm{p}<0.001)$ according to Pearson's correlation significance test.

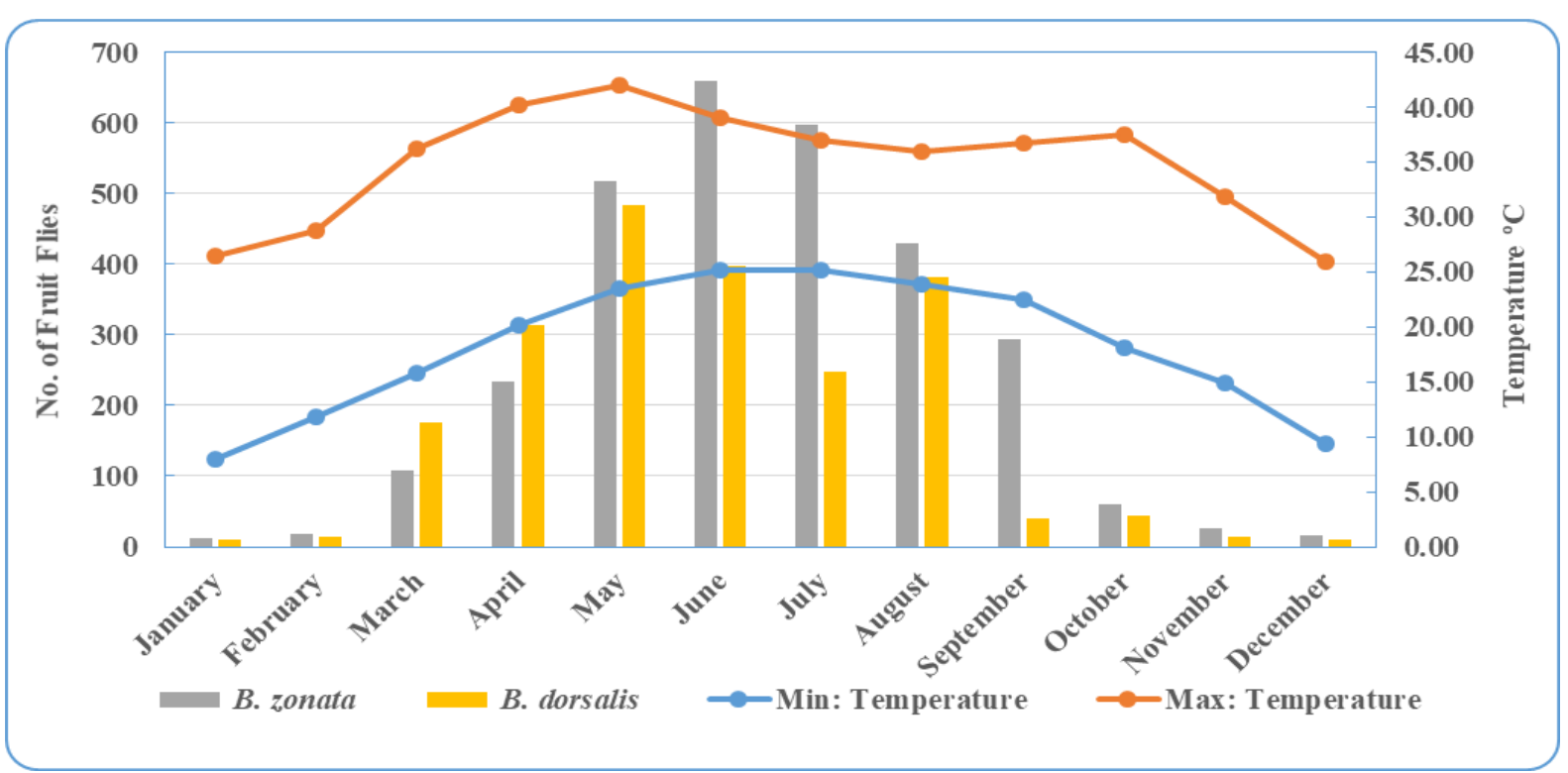

Figure 1. Showing influence of temperature $\left({ }^{\circ} \mathrm{C}\right)$ on population of Bactrocera spp. in mango orchard agro-ecosystem in district Hyderabad.

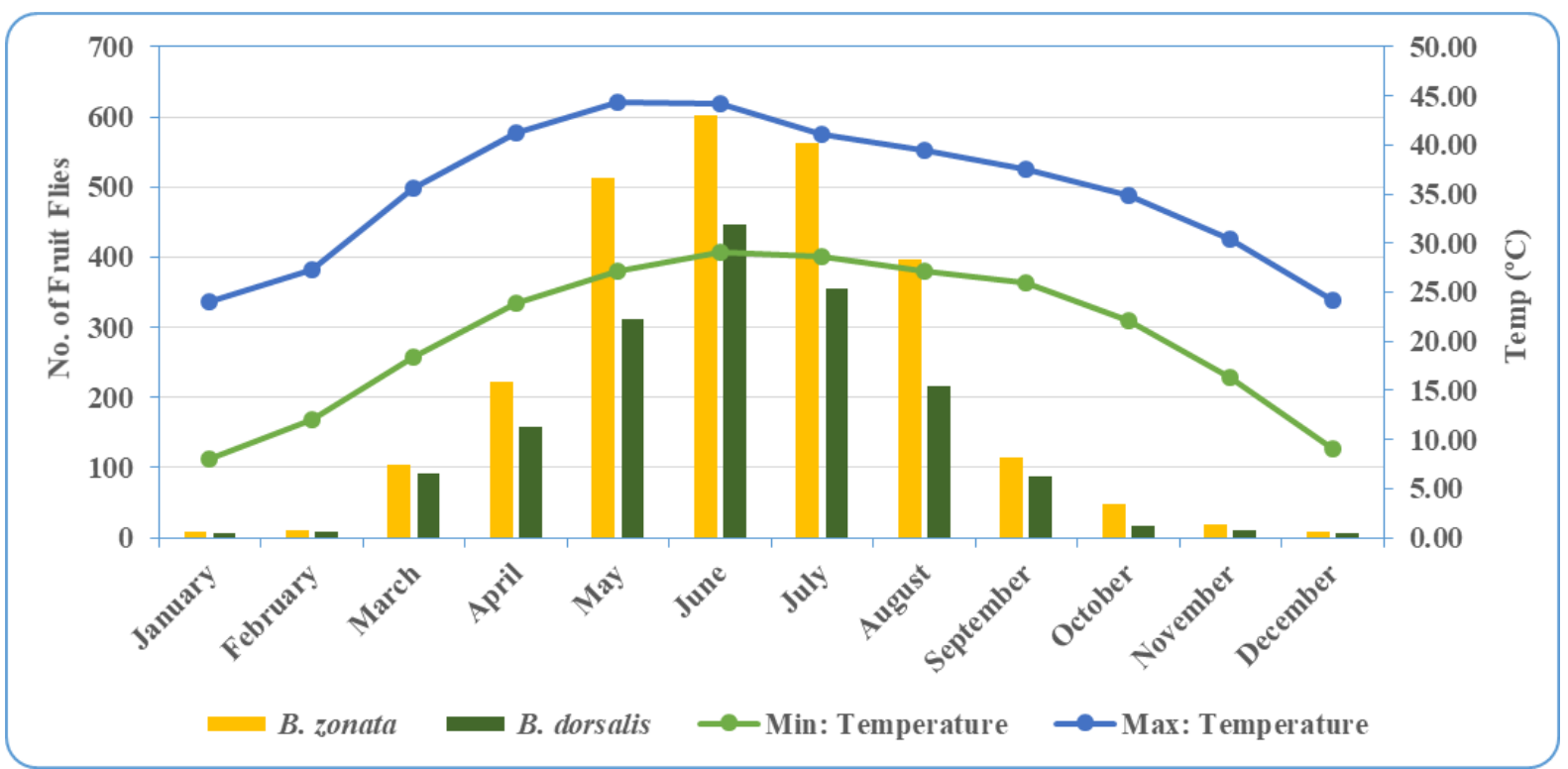

Figure 2. Showing influence of temperature $\left({ }^{\circ} \mathrm{C}\right)$ on population of Bactrocera spp. in mango orchard agro-ecosystem in district Larkana. 


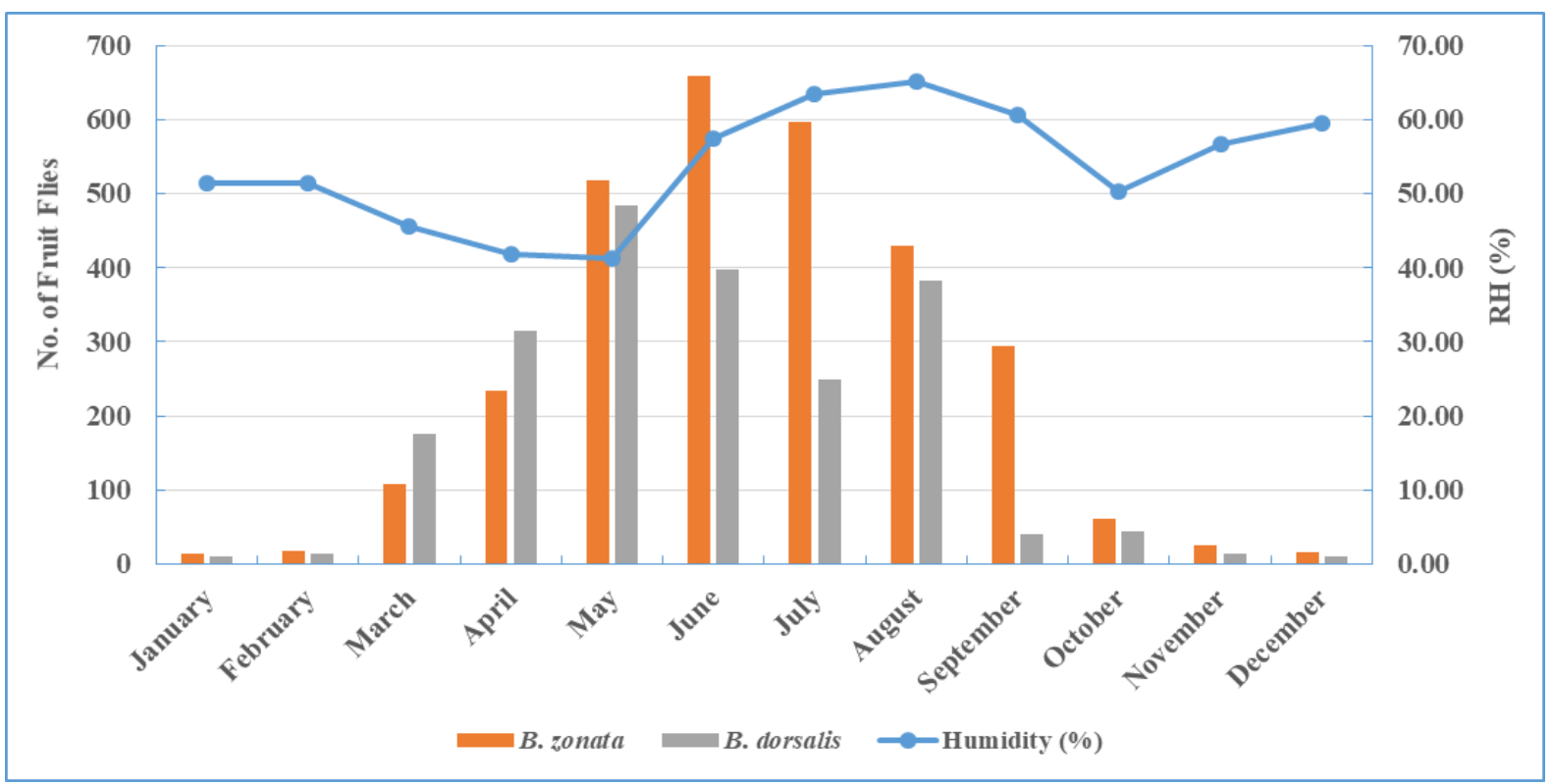

Figure 3. Showing influence of relative humidity (\%) on population of Bactrocera spp. in mango orchard agro-ecosystem in district Hyderabad.

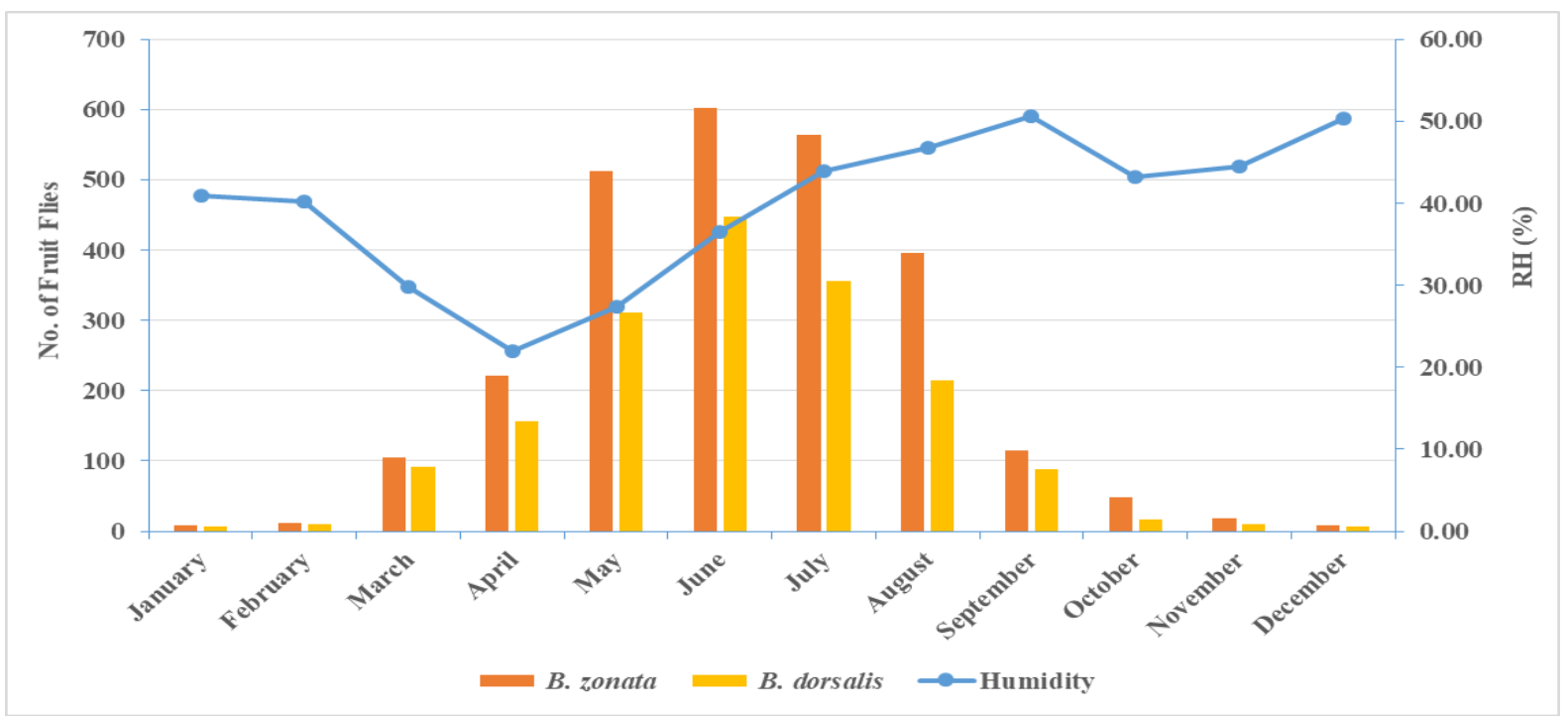

Figure 4. Showing influence of relative humidity (\%) on population of Bactrocera spp. in mango orchard agro-ecosystem in district Larkana.

Increase in temperature not only initiated the ripening of fruits but had also substantial effects on population of Bactrocera flies by increasing it as reported in previous studies $[12,13]$.

In India and Yunnan Province of China the peak population of peach fruit fly (357.0 flies/trap) and oriental fruit fly (342.0 flies /trap) were recorded in June $[14,15]$. Our present findings are partially similar with the reports of the previous investigators.
The population of Bactrocera flies started to decline after September and significantly reduced in October to December in studies areas. Similarly, researchers [16] also stated that the decline in Bactrocera species population was observed in the month of October and November. In addition, researchers [17] also noted a low population of Bactrocera flies from November to February. 
The population of B. zonata and B. dorsalis remained fluctuating throughout the year in the Hyderabad and Larkana regions. No significant differences in minimum population of Bactrocera flies in both climatic regions were recorded during December to March because of flowering and unripen fruit and low temperature. However, build up in the population of Bactrocera species started from April. The factors increasing population build-up of Peach fruit fly and Oriental fruit fly are due to favorable temperature and also in line with fruit availability on plants [18]. The availability of host fruits and abundance of alternative hosts surrounding experimental area are important factors which also contribute to the population buildup of Bactrocera species [19, 20]. Similarly in our studies in Hyderabad region the mango orchards were surrounded by guava orchards where high population of both Bactrocera species were observed as compared to Larkana region where mango orchards were surrounded by wheat and rice fields around the year.

The positive correlation between Bactrocera flies population and temperature was observed at both districts whereas relative humidity had a slightly negative effect on Bactrocera flies at both climatic zones as supported by other report from [21] whereas, researchers [22] also reported a positive correlation of minimum and maximum temperature and negative correlation of relative humidity with population densities of $B$. cucurbitae in district Hyderabad. Similarly, positive correlation of the fruit fly with temperature was reported by [23]. Our results are in agreement with these previous researchers.

\section{Conclusion}

In present studies the observations were made on population fluctuations of Peach Fruit Fly and Oriental Fruit Fly in different climatic zones of Sindh. The initially high population of both species were started from the first week of March in both zones respectively. High Temperature enhances the activity of Bactrocera species it depends on the accessibility to full-grown fruit. The population of both Bactrocera species reached to its highest peak in the June in mango orchards of Hyderabad and Larkana districts.

Studies from two sites situated in different ecological zones tell that activities of the both species of fruit fly are similar in population fluctuation. Moreover, quite significant difference of temperature (with 1 or 2 degree Celsius) and a difference of relative humidity (of 5 to $10 \% \mathrm{RH}$ ), the trend of both species do not vary. Thus, population trend remains positively correlated with rise in temperature and negatively correlated with increase in relative humidity.

From the above investigations it is concluded that during periods of high temperature and high relative humidity, it is the time to pay extra attention to articulate MAT for a sustainable pest management program for fruit flies management in mango orchards of both climatic zones.

\section{Authors' contributions}

Conceived and designed the experiments:

N Baloch, RM Memon \& NH Khuhro, Performed the experiments: ZA Abro \& QA Soomro, Analyzed the data: ZA Abro, Contributed materials/ analysis/ tools: RM Memon \& NH Khuhro, Wrote the paper: ZA Abro.

\section{References}

1. Naqvi MH (2005). Management and quality assurance of fruits and vegetables for export needs for product to market approach. Use of Irradiation for Quarantine Treatment of Fresh Fruits and Vegetables: 14-24.

2. Tan KH \& Nishida R (1998). Ecological significance of a male attractant in the defence and mating strategies of the fruit fly pest, Bactrocera papayae. Ent Exp Appl 89: 155-158.

3. Lux SA, Ekesi S, Dimbi S, Mohamed S, \& Billah MK (2003a). Mango infesting fruit flies in African-perspectives and limitations of biological approaches to their management: 277-293.

4. White IM. \& Elson Harris MM (1992). Fruit flies of economic significance: 
their identification and bionomics. CAB International, Wallingford. U.K.: 601.

5. Liquido NJ, Cunningham RT \& Nakagawa S (1990). Host plants of Mediterranean fruit fly (Diptera: Tephritidae) on the Island of Hawaii (1949-1985 Survey). J. Econ Ent 83: 1863-1878.

6. Report Pakistan Bureau of Statistics (PBS), (2017). :105-106.

7. Ekesi S \& Billah MK (2006). A Field guide to the management of economically important tephritid fruit flies in Africa. ICIPE Science Press, Nairobi, Kenya.

8. Hashem AG, El-Wakad MF \& Soliman NA (2004). The fruit flies. Egyptian Agriculture Ministry, The Agricultural Guidance Division, Egypt: 1-35.

9. French C (2005). The new invasive Bactrocera species, In Insect Pest Control Newsletter, No. 65. International Atomic Energy Agency, Vienna, Austria: 19-20.

10. Drew RAI, Tsuruta $K$ \& White IM (2005). A new species of pest fruit fly (Diptera: Tephritidae: Dacinae) from Sri Lanka and Africa. Afr Entomol 13: 149154.

11. Mwatawala MW, Meyer D, Makundi MRH \& Maerere AP (2006). Biodiversity of fruit flies (Diptera: Tephritidae) in orchards in different agroecological zones of the Morogoro region, Tanzania. Fruits 61: 321-332.

12. Khan RA \& Naveed M (2017). Occurrence and Seasonal Abundance of Fruit Fly, Bactrocera zonata Saunders (Diptera: Tephritidae) in Relation to Meteorological Factors. Pak J Zool 49(3): 999-1003.

13. Duyck PF, David P, Junod G, Brunel C, Dupont R, \& Quilici S (2006). Importance of competition mechanisms in successive invasions by polyphagous tephritids in La Re'union. Ecol 87: 17701780.

14. Agarwal ML \& Kumar P (1999). Effect of weather parameters on population dynamics of peach fruit fly, Bactrocera zonata (Saunders). Entomol 24: 81-84.

15. Ye H (2001) Distribution of the oriental fruit fly (Diptera: Tephritidae) in Yunnan province. Ent Sin 8: 175-182.

16. Mahmood K \& Mishkatullah (2007). Population dynamics of three species of Bactrocera (Diptera: Tephritidae: Dacinae) in BARI, Chakwal (Punjab). Pakistan J Zool 39: 123-126.

17. Makhmoor HD \& Singh ST (1998). Effect of concentration of methyl eugenol for the control of guava fruit fly, Dacus dorsalis Hendel in guava Orchard. Annls Pl Protect Sci 6: 165169.

18. Win NZ, Mi KM, Oo TT, Win KK, Park J \& Park JK (2014). Occurrence of fruit flies (Diptera: Tephritidae) in fruit orchards from Myanmar. Korean J Appl Ent 53: 323-329.

19. Papadopoulos NT (1999). Study on the biology and ecology of the Mediterranean fruit fly Ceratitis capitata (Diptera: Tephritidae) in northern Greece. PhD dissertation, Aristotle University of Thessaloniki, Thessaloniki, Greece.

20. Drew RAI \& Hooper GHS (1983). Population studies of fruit flies (Diptera: Tephritidae) in South East Queensland. Oecologia (Berl) 26: 153-159.

21. Amice R \& Sales F (1997). Seasonal abundance of fruit flies in New Caledonia. In: Management of fruit flies in the Pacific (eds. AJ Allwood and RAI Drew). ACIAR Proc 76: 134-139.

22. Kannan M \& Venugopala RN (2006). Ecologicoal studies on mango fruit fly, Bactrocera dorsalis Hendel. Annls. Pl Protect Sci 14: 340-342.

23. Abro ZA, Baloch N, Khuhro NH, Qazi WA \& Saeed NA (2017). Population densities of melon fruit fly Bactrocera cucurbitae (Coquillett) in vegetables agro-ecosystem in District Hyderabad, Sindh, Pakistan. Sarhad J of Agric 33(2): 331-337. 